\title{
Pollinators diversity for tomatoes crop under agro-forest ecosystem of Dera Ghazi Khan Punjab Pakistan
}

\author{
Muhammad Amjad Bashir ${ }^{1 *}$, Abid Mahmood Alvi ${ }^{1}$, Muhammad \\ Ishaq Asif Rehmani ${ }^{1}$, Tahira Batool Qasirani ${ }^{2}$, Shahzadi Mahpara ${ }^{3}$ \\ and Muhammad Tariq ${ }^{1}$
}
1. Department of Plant Protection Faculty of Agricultural Sciences Ghazi University DG Khan Punjab-Pakistan
2. Department of Agriculture Engineering and technology Faculty of Agricultural Sciences Ghazi University DG
Khan Punjab-Pakistan
3. Department of Plant Breeding and Genetics Faculty of Agricultural Sciences Ghazi University DG Khan Punjab-
Pakistan

*Corresponding author's email: amjadhajbani@hotmail.com

Citation

Muhammad AmjadBashir, Abid Mahmood Alvi, Muhammad Ishaq Asif Rehmani, Tahira Batool Qasirani, Shahzadi Mahpara and Muhammad Tariq. Pollinators diversity for tomatoes crop under agro-forest ecosystem of Dera Ghazi Khan Punjab Pakistan. Pure and Applied Biology. Vol. 8, Issue 2, pp1487-1493.

http://dx.doi.org/10.19045/bspab.2019.80088

\begin{tabular}{llll}
\hline \hline Received: 03/11/2018 & Revised: 29/04/2019 & Accepted: 02/05/2019 & Online First: 13/05/2019 \\
\hline \hline
\end{tabular}

\section{Abstract}

Pakistan is a country where very little is known about the biodiversity of insect pollinators and their interaction with flowering plants. Insect pollinators are the amongst our natural resources because pollination is the most important ecosystem service performed by the insects and plays a vital role in the socio-economic status of human being. The given study was carried out in an agroforest ecosystem of Dera Ghazi Khan to evaluate the insect pollinators' diversity. Insect pollinators were collected from the flowers of tomatoes with the help of a hand net. Two species (Amegilla cingulate and A. chlorocyanea) of Amigella bees were found on the flowers abundantly followed by Giant honey bee (Apis dorsata) was also observed on the flowers of the tomato. Small honey bees (Apis mellifera., Apidae: Hymenoptera) were observed on the flowers and were captured successfully with the help of a hand net. The data were taken at the morning time when the weather was clear and sunny approximately at about $10 \mathrm{am}-12 \mathrm{pm}$. As these insects belong to family Apidae and order Hymenoptera.. These bees visit the flowers abundantly and pollinate the flowers successfully. These insects were the main visitors of the tomato flowers but many other insects like Butterflies, moths, cabbage butterflies, Syrphid flies, earth wasps, carpenter bees, Skippers and Helicted bees were also observed and collected with the help of a hand net. Our results showed that pollinators may the increase in quantity and quality of the tomato fruit in the open field due to these pollinators.

Keywords: Diversity; Insect; Pollinators; Tomatoes; Yield

\section{Introduction}

Tomato (Lycopersicon esculentum) is the most common and broadly used vegetable which is grown all over the World. The suitable temperature in summer and relative humidity increase the production of tomato 
throughout the year. Tomato needs different methods of pollination to enhance its yield and nutritive value. It is clear now a day that pollination methods in many areas of agriculture are endangered by the absence of sustainable agriculture executive [1].

Lack of pollinators in an area can decrease the yield of tomato. Flower pollinators for example birds, bats honey bees, and insects play crucial role in pollination and production of most vegetables and fruits .Without the assist of pollinators most plants cannot breed and most farmers face a great yield loss. In actual fact about $90 \%$ of all the flowering plants depend on animal pollination [2-3]. Many insects deliver important ecology facilities to horticulture crops, including pest control and pollination of crops [4-5].

Tomatoes are highly perishable but large quantities of tomatoes are wasted due to poor storage facilities. About $99 \%$ tomatoes are self-pollinated [6]. The flowers of most cultivars have a short cycle that spaces the stigma healthy inside the anther tube, promising self-pollination and almost removing the chance for out crossing [7].

Tomatoes are usually consumed at their full maturity and when color is red but before becoming soft. The color of the fruit is important for fruit picking and usage and this color is considered the most important external characteristic for fruit selection and for postharvest life. This fruit color plays an important role in the market for consumer's decision to purchase the tomato fruits. When red color of the tomato fruit appears it indicates the degradation of the chlorophyll as well as production of lycopene and other carotenoids, as chromoplasts are made from the chloroplasts [8].

Different products like paste juice and ketchup are made from tomato and are widely consumed all over the World. Tomato is a rich source of vitamin $\mathrm{C}$ and vitamin $\mathrm{A}$ and tomato is used in various dishes. The demand for tomato is greatly increasing with the increasing population of the World. It is necessary to produce more tomatoes in the field to fulfill the requirements. Increase of the fast food production in the country is also playing a momentous influence on the demand for tomato products. It is understood that this movement will continue in the near future and the use of tomato will rise. The seasonal summer crop tomatoes are grown in open fields. They grow and reach maturity in warm places with plenty of sun light. Tomato is a type of vegetable which is most widely consumed vegetable as compared to all other vegetables in the world under field and greenhouse conditions [10].

In 2000 the share of Pakistan in the World tomato exports was insignificant. The consequences of worldwide and national tomato production and export showed the increase in production and export of tomato since 2007. Pakistan is producing tomatoes about $5 \%$ while growth rate of tomato is $8 \%$. So there are opportunities for tomato production and export. At present Pakistan depends on Middle East and Afghanistan markets for export of tomato. Therefore, it is essential and it is a need to search for other markets in the World for tomato spread [11]. Among cultivated crops like onion, chilies and tomato are most popular and most significant needs for human diet in Pakistan. These are baked with meat and with other vegetables and in addition to be used as salad. Therefore, the requisite of these vegetables is inflexible in Pakistan [12].

China is at the top position in tomato production and producing tomatoes in large amounts followed by Turkey, India, Iran and Bangladesh. Tomato production rate for last decade designates highest value 9\% for Sri Lanka followed by Kazakhstan and Azerbaijan $8 \%$. While tomato production in china was $7 \%$ and production of tomato in India and Pakistan was 5\%. Total are for the production of tomato has improved from 
4022729 ha to 4837576 ha from 2000 to 2008 [13]. Pakistan supplies chilies, onion and tomato which are major vegetable crops and play a vital role in human diet. Therefore, the present crops are responsible to provide great benefits to farmers and create opportunities for employment to rural people as these crops require more labor inputs as compared to other crops because these need great care for maximum yield. [14].

Pakistan in 2004-2005 exported fruits and vegetables to many countries like United Kingdom, India, Dubai, Saudi Arabia and Afghanistan [15]. In Northwest Europe about $80 \%$ of the flowering plants depend on insects for their reproduction and pollination and are responsible to increase the yield [16]. The pollination success of these plant species depends on the activity of insects that visit and pollinate the flowers successfully. Every insect pollinator has its own efficiency of pollination of the flowers, based on behavioral features like foraging speed, flower constancy, pollen load on the body, pollen collection and pollen transfer to the stigma.

In Pakistan, tomato is cultivated on about the land of 53.4 thousand ha while producing about 561.9 thousand tons of tomato and the share of the province Punjab is 5.6 thousand ha which is producing 72.5 thousand tons of tomatoes and causing a higher yield of 12.9 tons/ha in Punjab as compared to average of the country. The export worth of tomato is 12453 thousand rupees and the quantity is about $997147 \mathrm{~kg}$. Similarly, the import price of tomato is 502286 thousand rupees and the quantity recorded is $35860265 \mathrm{~kg}$ [17]. Pakistan is a country where very little is known about the biodiversity of insect pollination and their interaction with flowering plants. Insect pollinators are the amongst our natural resources because pollination is the most important ecosystem service performed by the insects and plays a vital role in the socio-economic status of human being. Because of its yield enhancing benefits, insect pollination can play a significant role in keeping a defensible and sustainable agriculture with minimized disturbance to environment [18]. The financial importance of insect pollination goes beyond production agriculture because insects pollinate more than one crop plants. Without knowing the natural resource of our pollinators and flowering plants, we may not be able to know about endangered species and threats to our natural ecosystems.

Keeping in view the importance of tomato crop and the role of pollination methods and pollinators diversity in their yield and nutrition value this study was planned.

\section{Materials and methods}

The experiment was conducted to study the pollinators diversity at flowering stage. Different pollinators were observed on the flowers of the tomato and were captured with an aerial net. These were identified and were pinned in the collection box and submitted in the College of agriculture Dera Ghazi Khan.

\section{Study area}

To study the Influence of Pollinators biodiversity on yield and nutrition of tomatoes, we have selected the one of the richest vegetable growing area of the Dera Ghazi Khan which is near to the Indus River, located in the revenue boundary of mouza Gaddai Gharbi having mix culture of forest and agriculture.

\section{Duration and climatic condition}

The study was conducted in the different farmers' fields of Dera Ghazi Khan with agro ecological environment. Weather of the area is subtropical with a hot summer and cold winter; the mean daily maximum and minimum temperatures and humidity are in the range of $12^{\circ} \mathrm{C}$ to $42{ }^{\circ} \mathrm{C}$ and $21 \%$ to $65 \%$ respectively with the mean monthly summer rain fall of $18 \mathrm{~mm}$. The experiment was performed from February 2014 to May 2014 and the sampling was done fortnightly; 
however, the data was taken in clear sunny days excluding cloudy and rainy days.

\section{Data collection}

Four rows of about 40 plants were surveyed in each treatment for 2 hours and the presence of pollinators was recorded and quantified. The number of visits per pollinator species were recorded. Flower visitors were collected for identification. When collection was not possible, the insects were killed in the poison bottle. Those data were collected during two separate days in each property to make for statistically applicable sampling results. Our filed studies took place between 09:00am and 12:00pm, which is when previous data indicated peak floral visitation and greatest amount of pollen available for pollination in the anthers. A thorough collection of pollinators was done in the study areas. Fortnightly collections of pollinators were made throughout the study period by using standardized protocol i.e. sweep netting and data was taken twice a day, when the blooming of the tomatoes flowers was at its peak. Most of the flower visitors were bees, wasps, butterflies and flies. The collected insects were pinned and labeled indicating locality (GPS position), date and host plant (Tomato). The family level identification was done by using keys proposed by Borer [19].

\section{Results}

This basic information is necessary in predicting future conservation of priority pollinator species. This this study was designed so that we can manage a comprehensive list of pollinators. According to our results overall 14 different hexapods species of tomato pollinators were monitored representing from three different orders (Lepidoptera, Diptera \& Hymenoptera) with eight insect families Nymphalidae, Pieridae, Hesperiidae, Syrphidae, Apidae, Anthophoridae, Vespidae, Helictidae. Among these, order Hymenoptera was the most abundant with four families and seven species and the order Diptera was the least abundant with one family and two species, similarly among families, the family Apidae was the most abundant one representing five species. A comprehensive list of the pollinator' biodiversity is also included (Table $1 \&$ Figure 1).

Table 1. A comprehensive list of pollinators biodiversity of the tomato crop representing common name, technical name, family with order

\begin{tabular}{|c|c|c|c|}
\hline Common Name & Technical Name & Family & Order \\
\hline $\begin{array}{c}\text { Ak butterfly/Monarch } \\
\text { butterfly }\end{array}$ & Danausplexippus & Nymphalidae & Lepidoptera \\
\hline Cabbage butterfly sp1 & Pierisbrassicae & Pieridae & Lepidoptera \\
\hline Cabbage butterfly sp2 & pierisrapae & Pieridae & Lepidoptera \\
\hline Skipper & Hesperia comma & Hesperiidae & Lepidoptera \\
\hline Syrphid fly sp1 & Syrphus sp. & Syrphidae & Diptera \\
\hline Syrphid fly sp2 & Allograpta sp. & Syrphidae & Diptera \\
\hline Giant honey bee & Apis dorsata & Apidae & Hymenoptera \\
\hline Small honey bee & Apis mellifera & Apidae & Hymenoptera \\
\hline Carpenter bee sp1 & Xylocopa sp.1 & Anthophoridae & Hymenoptera \\
\hline Carpenter bee sp2 & Xylocopa sp.2 & Apidae & Hymenoptera \\
\hline Yellow Wasp & Vespa orientalis & vespidae & Hymenoptera \\
\hline Amigella bee sp1 & Amegilla cingulata & Apidae & Hymenoptera \\
\hline Amigella bee sp2 & Amegilla chlorocyanea & Apidae & Hymenoptera \\
\hline Halicted bee & Halicted sp. & Halictidae & Hymenoptera \\
\hline
\end{tabular}




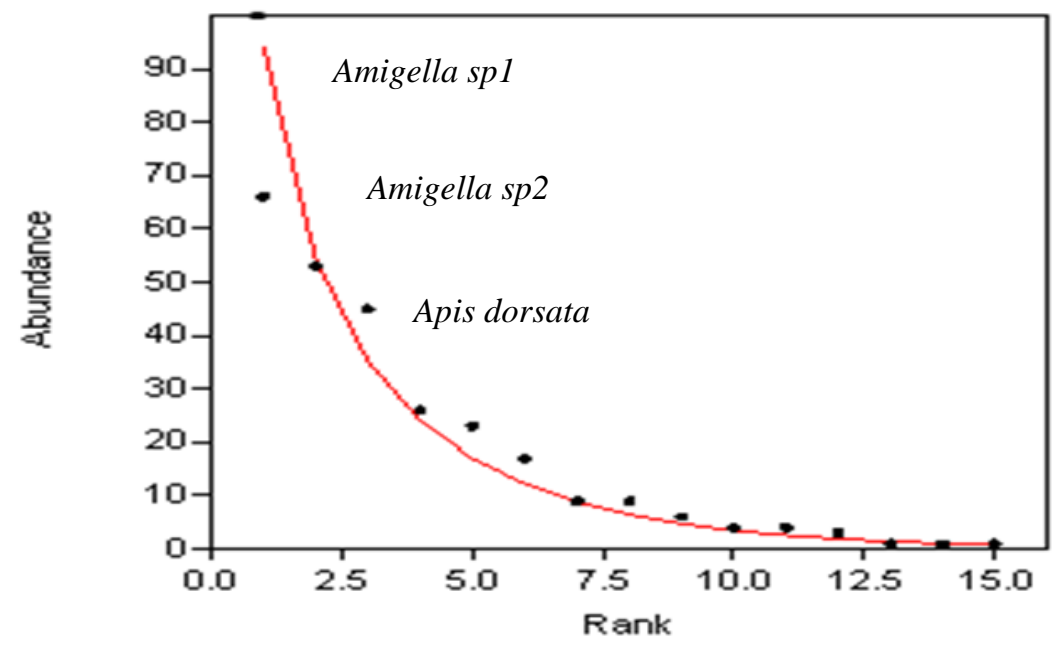

Figure 1. Rank abundance curve of tomato pollinators species showing the richest in form of numbers of individuals

\section{Discussion}

Regarding richness of the pollinators we have used the rank abundance curve of insect pollinators species of tomato crop which show that there were many species with less abundance while only few species with much higher abundance. The top most abundant species included Amigella sp1, Amigella sp2 and Apis dorsata respectively while the Ak butterfly, Yellow wasp and Earth wasp were the least abundant pollinators species for the experimental crop. Different insect pollinator species were observed in the open field. These species were Amigella species like Amegilla cingulate and Amegilla chlorocyanea ,yellow wasps, Giant honey bee (Apis dorsata) and small honey bee (Apis mellifera),Cabbage butterflies i.e. Pierisbrassicae, pierisrapae, Monarch butterfly/ak butterfly Danausplexippus, Skipper Hesperia comma, Syrphid fly1 Syrphus sp. Syrphid fly2 Allograpta sp., Carpenter bee1Xylocopa sppl Carpenter bee2 Xylocopa sp. 2, Earth wasp , Halicted bee Halicted sp. Among these species the Amigella bees and Honey bee found to be very abundant in the tomato field. A 30 years assemblage of communities of ants at $\mathrm{La}$
Selva, Cost Rica has still not reached an asymptote in species richness [20]. However, flies in my study reached an asymptote. Among bees in this study, family Halictidae was species most rich and abundant one while family Andrenidae was species least rich and least abundant one. Halictid bees are more abundant than most bees with the exception of Apis (honey bee) species [21]. Few studies from Pakistan also have shown similar trends i.e. comparatively high species richness of Halictid bees in agricultural ecosystems of Pakistan however, Apis dorsata and A. florea had the superiority in terms of abundance [22-24].

The foraging behavior of Amegilla chlorocyanea makes it easier to visit the tomato flowers easily and to pollinate them. However, its population may be interfered due to harsh environmental conditions and use insecticides. Honey bees have been found more in number in the open field due to their favorable environment and their hives have been located in nearby areas. Yellow wasps and other insects were less in number but found on flowers and observed pollinating the flowers successfully. Pollinatotrs biodiversity was studied and a 
comprehensive list of the pollinators was made. Insects play a vital role in pollination of the tomato crop. In the present study the following species were observed Amigella species like Amegilla cingulate and Amegilla chlorocyanea, yellow wasps, Giant honey bee (Apisdorsata) and small honey bee (Apis mellifera), Cabbage butterflies i.e. Pierisbrassicae, pierisrapae, Monarch butterfly/ak butterfly Danausp lexippus, Skipper Hesperia comma, Syrphid fly1Syrphus spp Syrphid fly2 Allograptaspp, Carpenter bee1Xylocopa sppl Carpenter bee 2 Xylocopa sp.2, Earth wasp, Halicted bee Halicted spp. Among these species the Amigella bees and Honey bee found to be very abundant in the tomato field. Resultantly these visitors increased the yield and nutrition of the tomato crop. Family Syrphidae, on the other hand, proved to be the species most rich and abundant family among Diptera files followed by family Calliphoridae and Empididae. Family Syrphidae perhaps is most widely studied family among flies in Pakistan. Several authors have reported Syrphid flies as the regular visitors of a number of agricultural and wild plant species in Punjab, Pakistan $[25,26]$. Hoverflies are the characteristic feature of spring season (March-April) in this part of Pakistan. [26] Reported interaction of 14 Syrphid fly species with 59 plant species throughout the year while [27] reported the relative effectiveness of different syrphid flies in pollination of onion, canola and bitter gourd crop, respectively.

\section{Conclusion}

Current study provides a baseline survey of species composition and assemblage structure of flower visiting Hymenoptera and Diptra insects for the first time from the four widely isolated nature reserves of southern Punjab, Pakistan. The study also identifies the species most rich and most abundant families of bees, wasps and flies. This baseline study will provide basic information to ecologists for opening new investigations regarding complexity of species interactions i.e. plant and pollinator interactions, and devising management and conservation strategies.

\section{Authors' contributions}

Conceived and designed the experiments: MA Bashir, AMI Asif \& S Mahpara, Performed the experiments: M Tariq \& TB Qasirani, Analyzed the data: MA Bashir, Contributed materials/ analysis/ tools: TB Qasirani \& S Mahpara, Wrote the paper: TB Qasirani \& MA Bashir.

\section{References}

1. Kevan PG \& Phillips TP (2001). Economic impacts of pollinator declines: An approach to assessing the consequences. Conserve. Ecol Uni Guelph.

2. Free JB (1993). Insect pollination of crops. Academic press, London, UK.

3. Buchmann SL \& Nabhan GP (1996). The forgotten pollinators. Island Press, Washington.

4. Tscharntke T, Klein AM, Kruess A, Steffan. DI \& Thies C (2005). Landscape perspectives on agricultural intensification and biodiversityecosystem service management. Ecol Letters 8: 857-874.

5. Losey JE \& Vaughan M (2006). The economic value of ecological services provided by insects. Biol Sci 56: 311323.

6. McGregor SE (1976). Insect pollination of cultivated crop plants. US Deptt Agric Res Serv Handbook No. 496, Washington, DC. USA.

7. Rick CM (1978). The tomatoes. Sci Amer 239(2):76-89.

8. Fraser PD, Truesdale MR, Bird CRW \& Bramiley PM (1994). Carotenoid biosynthesis during tomato fruit development. Plant Physiol 105: 405413. 
9. Kaloo G (1986). Tomato (Lycopersicon esculentum Miller). Allied publishers Pvt.Ltd, New Delhi, pp 203-220.

10. Tahir, Shah AH, Sharif M, Akhtar W \& Akmal N (2012). An overview of tomato economy of Pakistan: Comparative analysis. Pak J Agric Res 25(4): 288294.

11. Lohano HD \& Mari FM (2005). Spatial price linkages in regional onion markets of Pakistan. J Agric Soc Sci 1(4): 318321.

12. FAO (1993). Citrus fruit- fresh and processed annual statistics. CCP; CI/ST/93- Rome, Italy.

13. Mari FM, Rajab AM \& Lohano HD (2007). Measuring returns to scale for onion, tomato and chilies production in Sindh province of Pakistan. Inter J Agric Biol 9(5):788-790.

14. EBP (1996). Biodiversity Profile of Nepal with special reference to protected area. Dept. of National Park and Wildlife Conservation HMG/Nepal.

15. Mari FM, Rajab AM \& Lohano HD (2007). Measuring returns to scale for onion, tomato and chilies production in Sindh province of Pakistan. Inter J Agric Biol 9(5): 788-790.

16. Kwak M (1994). Planten en bestuivers: achteruitgang leidt tot verschuivende relaties. Lands Chap 11(1): 29-39.

17. Gvernment of Pakistan (GOP). (2008). Agricultural statistics of Pakistan. Economic wing ministry of food, agriculture and livestock, Islamabad Pakistan.

18. Borror DJ, Long DM \& Triplehorn CA (1981). An introduction to the study of insects. Saunders College Publishing, Philadelphia.

19. Longino JT, Coddington J \& Colwell RK (2002). The ant fauna of a tropical rain forest: estimating species richness three different ways. Ecol 83: 689-702.

20. Michener CD (2007). The bees of the world, second edition. Baltimore, pp 913.

21. Ali M, Saeed S, Sajjad S \& Whittington A (2011) in search of the best pollinators for canola (Brassica napus L.) production in Pakistan. Appl Entomol Zool 46: 353-361.

22. Saeed S, Malik, Dad K, Sajjad A \& Ali M (2012) In Search of the Best Native Pollinators for Bitter Gourd (Momordica charantia L.) pollination in Multan, Pakistan. Pak J of Zool 44(6): 16331641.

23. Ali M, Saeed S, Sajjad S \& Bashir MA (2014) Exploring the best native pollinators for pumpkin production in Punjab Pakistan . J of Zool 46(2): 531539.

24. Sajjad A, Saeed S, Muhammad W \& Arif MJ (2009) Role of insects in crosspollination and yield attributing components of Sesbania sesban. International. J of Agricu and Biol 11(1): 77-80.

25. Sajjad A \& Saeed S (2010). Floral host plant range of Syrphid flies (Syrphidae: Diptera) under natural conditions in southern Punjab, Pakistan. Pak J of Bot 42(2): 1187-1200.

26. Saeed S, Sajjad A, Kwon O \& Kwon YJ (2008) Fidelity of Hymenoptera and Diptera pollinators in onion (Allium cepa L.) pollination. Entomol Res 38: 276280.

27. Sajjad A, Saeed S \& Bashir MA (2012). Spatial variation in pollinator communities and reproductive performance of Prosopis juliflora. $J$ of Pollination Ecol 8(9): 59-66. 